\title{
INSERÇÃO PROFISSIONAL DOS EGRESSOS DE UM CURSO DE EDUCAÇÃO FÍSICA COM ÊNFASE NA FORMAÇÃO EM SAÚDE
}

\author{
PROFESSIONAL INSERTION OF THE GRADUATES FROM A PHYSICAL \\ EDUCATION COURSE WITH EMPHASIS ON HEALTH TRAINING
}

\author{
EMPLEABILIDAD DE LOS GRADUADOS DE UN CURSO DE EDUCACIÓN \\ FÍSICA CON ÉNFASIS EN LA EDUCACIÓN PARA LA SALUD
}

\author{
Luana de Oliveira Candido ${ }^{1}$ \\ Rosana Aparecida Salvador Rossit ${ }^{2}$ \\ Rogério Cruz de Oliveira ${ }^{3}$
}

Resumo Os objetivos do estudo foram compreender a inserção profissional dos egressos de um curso de Educação Física com ênfase na formação em saúde na perspectiva do Sistema Único de Saúde e analisar a relação desta inserção com a formação interdisciplinar e interprofissional proposta pela instituição - no caso, a Universidade Federal de São Paulo - Campus Baixada Santista. Para tanto, em 2012, foi desenvolvida uma pesquisa exploratória de abordagem qualitativa que analisou parte do banco de dados de um estudo que objetivou avaliar o projeto de educação interprofissional na formação com ênfase em saúde da instituição. Da amostragem total dessa pesquisa (107 voluntários), foram incluídos nesse estudo 15 egressos do curso de Educação Física formados nas $1^{\mathrm{a}}$ e $2^{\mathrm{a}}$ turmas. A análise dos dados foi realizada por categorias não apriorísticas. Os resultados demonstraram que os egressos foram inseridos em áreas comuns à Educação Física (academias de ginástica, personal trainer, avaliação física, entre outros), na pós-graduação e, em menor frequência, na perspectiva do Sistema Único de Saúde. Conclui-se que ainda é pequena a inserção de profissionais de Educação Física no Sistema Único de Saúde, mesmo para um curso com essa ênfase.

Palavras-chaves educação física; profissional de saúde; formação profissional; inserção profissional.
Abstract The objectives of the study were to understand the employability of the graduates from a Physical Education course with emphasis on health training from the perspective of the Unified Health System and to analyze the relationship between this insertion and the interdisciplinary and interprofessional training proposed by the institution - in this case, the Federal University of São Paulo - Baixada Santista Campus, São Paulo, Brazil. For that, in 2012, an exploratory qualitative research was developed, which analyzed part of the database of a study that aimed to evaluate the interprofessional education project in the health training program of the institution. From the total sample of this research (107 volunteers), 15 graduates from the Physical Education course, formed in the 1st and 2nd classes, were included in the study. Data analysis was performed by a posteriori categories. The results showed that the graduates were inserted in areas common to Physical Education (gymnastic academies, personal trainer, physical evaluation, among others), in postgraduation and, less frequently, in the Unified Health System environment. It is concluded that the employability of Physical Education professionals in the Unified Health System is still small, even for a course with this emphasis.

Keywords physical education; health personnel; staff development; employability. 


\section{Introdução}

Na década de 1980, a Educação Física (EF) passou por uma crise epistemológica, a qual Ramos et al. (2008) descreveram como um momento de calorosos debates sobre formação profissional e campos de atuação. De acordo com os mesmos autores, soma-se ainda a discussão sobre o objeto de estudo da EF e os seus usos ideológicos.

No fim dessa mesma década, entrou em vigor a resolução n. 03/87 (Brasil, 1987), que possibilitou aos cursos de EF uma grande flexibilidade curricular, e cada Instituição de Ensino Superior (IES) pôde organizar suas disciplinas de acordo com os interesses e necessidades da região em que está inserida (Betti e Betti, 1996; Collet et al., 2009). A ideia de flexibilidade foi uma reação à resolução que antecedeu a esta - resolução n. 69/1969 (Souza Neto et al., 2004) - e que previa fortalecer e homogeneizar os cursos de formação inicial, padronizando a duração e a estrutura curricular do curso, no âmbito nacional.

A partir da resolução n. 03/87, a formação em EF ficou dividida em duas especialidades com distintos campos de atuação (Benites, Souza Neto e Hunger, 2008; Souza Neto et al., 2004). Em síntese, a licenciatura, com o objetivo de habilitar profissionais para trabalhar no contexto escolar, e o bacharelado, para a atuação profissional no contexto não escolar, tais como clubes, academias, etc. (Benites, Souza Neto e Hunger, 2008; Souza Neto et al., 2004)

Esta mudança atribuiu a condição de carga horária mínima de 2.880 horas com tempo mínimo de quatro anos para o cumprimento do curso (Betti e Betti, 1996; Souza Neto et al., 2004). Destas, $80 \%$ representavam a Formação geral (temas considerados necessários para um profissional da área) e $20 \%$, o Aprofundamento de conhecimento (estudos aprofundados na área escolhida - licenciatura ou bacharelado) (Ramos et al., 2008).

Para Betti e Betti (1996), essa reestruturação trouxe consigo dois modelos de formação: o tradicional-desportivo, que enfatiza as disciplinas denominadas 'práticas' (especialmente as esportivas). “Há separação entre teoria e prática. Teoria é o conteúdo apresentado na sala de aula (qualquer que seja ele), prática é a atividade na piscina, quadra, pista etc. A ênfase teórica se dá nas disciplinas da área biológica/psicológica (...)" (Betti e Betti, 1996, p. 10); e o técnico-científico, que valoriza as disciplinas teóricas e possui maior enlace com as Ciências Humanas e a Filosofia. “O conceito de prática é outro: trata-se de 'ensinar a ensinar' . (...) O conhecimento flui da teoria para a prática, e a prática é a aplicação dos conhecimentos teóricos" (Betti e Betti, 1996, p. 10).

De acordo com Tojal (2003), a formatação do currículo dos cursos de EF (divisão de licenciatura e bacharelado) foi consequência da mudança do mercado de trabalho, de interesses ideológicos corporativistas e da dinâmica de evolução da sociedade. Ou seja, a economia influenciou, de certa forma, os processos de modificação da formação profissional, percebendo-se que a 
EF foi se moldando para atender às necessidades e demandas do mercado (Ramos et al., 2008; Rezer e Nascimento, 2007). Souza Neto et al. (2004) acreditam que esta proposta foi semelhante a antiga (resolução 69/1969) e que isso se deve pelo 'contexto de difícil empregabilidade'. Já Benites, Souza Neto e Hunger (2008) afirmam que

em virtude de contemplar uma formação que não ficava restrita à escola, prevaleceu também a ideia de se constituir um corpo de conhecimento que desse maior legitimidade à própria profissão em seu processo de profissionalização (Benites, Souza Neto e Hunger, 2008, p. 347).

Além da instauração da resolução n. 03/87, outros fatos legais marcaram a EF no fim do século XX e impactaram as políticas de formação, como a criação da nova Lei de Diretrizes e Bases da Educação Nacional (LDB), n. 9.394/1996 (Brasil, 1996), a resolução n. 218/1997, que reconheceu o profissional de EF como um profissional da saúde, e a regulamentação da profissão a partir da lei n. 9696/1998 (Brasil, 1998).

Aliado a esse movimento, em 2004 o Conselho Nacional de Educação (CNE) instituiu as Diretrizes Curriculares Nacionais para os cursos de graduação em Educação Física, por meio da resolução n. 07/2004 (Brasil, 2004), que surgiu a partir da necessidade de uma releitura dos objetivos e da adequação dos conhecimentos e habilidades profissionais que cabem ao bacharelado em EF (Collet et al, 2009; Finoqueto, 2011). No entanto, Rezer e Nascimento (2007) afirmam que ainda não há consenso no que se refere às Novas Diretrizes Curriculares da EF e à formação desse profissional, e que o foco da discussão, dentre os profissionais da área, tem-se baseado na atuação dos egressos no mercado de trabalho. Atualmente, há uma minuta em discussão no Conselho Nacional de Educação que prevê uma nova Diretriz Curricular, propondo, inclusive, a extinção da modalidade de bacharelado (Oliveira e Andrade, 2016).

Frente a esse cenário, uma nova possibilidade foi gestada dentro dos cursos de formação em EF e nos campos profissionais: a atuação na saúde, principalmente impulsionada pelo reconhecimento da EF como profissão da saúde. Entretanto, mesmo com esta definição, a formação em EF ainda está baseada no pensamento tradicionalista, hospitalocêntrico e biomédico do processo saúde-doença (Fraga, Carvalho e Gomes, 2012; Brugnerotto e Simões, 2009). Encontra-se, também, a forma de organização curricular hierarquizada, centrada na transmissão de conhecimento (Fraga, Carvalho e Gomes, 2012).

Essa característica de formação hierárquica e o conceito de saúde limitado ao binômio saúde-doença tornam a atuação profissional da EF na saúde um tema extremamente complexo, baseando-se em pressupostos teóricos que tradicionalmente se distanciam da realidade prática e do cotidiano do Sistema Único de Saúde (SUS)(Fraga, Carvalho e Gomes, 2012). 
No entanto, esse distanciamento não existe somente na EF. Outras profissões na área da saúde também têm características formativas que dificultam a aproximação com o SUS, haja vista o pequeno número de disciplinas em seu currículo que discutem a saúde de forma mais ampliada e/ou a formação tradicionalmente centrada em disciplinas biológicas (Carvalho e Ceccim, 2012; Pasquim, 2010; Ribeiro e Medeiros Júnior, 2016). Tal quadro contribui para o distanciamento entre os profissionais formados e o indivíduo atendido. Carvalho e Ceccim (2012, p.159) afirmam que é comum nas disciplinas biológicas o trato com o "corpo morto" e não com sua dinâmica, estados e afetos. Os autores ainda afirmam que o contato com o "corpo vivo" se dá apenas no final do curso.

Nessa perspectiva, temos um profissional que atuará de forma reducionista no campo da saúde, distanciando-se dos preceitos de universalidade, integralidade e equidade do SUS.

No intuito de superação desse quadro, na implantação do novo campus da Universidade Federal de São Paulo, localizada na Baixada Santista (Unifesp-BS), o Projeto Pedagógico do Curso de Educação Física - PPCEF (Unifesp-BS, 2016) trilhou o viés da interdisciplinaridade ${ }^{4} \mathrm{e}$ da educação interprofissional, ${ }^{5}$ na tentativa de atender a novas perspectivas da área, tendo como objetivo geral do campus:

Formação de um profissional da área da saúde apto para o trabalho em equipe interprofissional, com ênfase na integralidade do cuidado ao sujeito; Formação técnico-científica e humana de excelência em uma área específica de atuação profissional de saúde (Unifesp-BS, 2016, p. 33).

Dessa forma, estruturou-se um currículo comum entre os cursos integrais da Unifesp-BS (Educação Física, Fisioterapia, Nutrição, Psicologia e Terapia Ocupacional), visando à formação interdisciplinar e interprofissional a partir de quatro eixos: O ser humano em sua inserção social; Trabalho em saúde; O ser humano em sua dimensão biológica; e Aproximação a uma prática específica em saúde.

Cada um desses eixos é formado por diversos módulos com áreas temáticas referentes. A parte específica da EF é abordada no eixo 'Aproximação a uma prática específica em saúde', a qual trabalha com conteúdos e atividades sistematizadas no horizonte da intervenção em serviços de saúde. É desenvolvida de forma crescente no decorrer do curso, chegando a ocupar toda a grade curricular no $4^{\circ}$ ano. A perspectiva é a de formar profissionais aptos a trabalhar nos espaços competentes ao bacharel, resguardando-se as recomendações gerais das diretrizes curriculares sugeridas pela resolução $\mathrm{n}$. 7/2004 (Unifesp-BS, 2016).

Quanto ao objetivo geral, o curso de EF pretende a formação de profissionais:

(...) aptos a diagnosticar, planejar, prescrever, orientar, assessorar, supervisionar, controlar e avaliar projetos e programas de atividades físicas, de exercícios físicos, 
de atividades recreativas e esportivas nas perspectivas da prevenção, promoção, proteção e reabilitação da saúde, por meio da atuação em equipes multidisciplinares (Uinfesp-BS, 2016, p. 27).

Para o perfil do egresso do curso de EF da Unifesp-BS é prevista a formação acadêmico-profissional generalista, humanista e crítica, capaz de refletir sobre a realidade, de modo a intervir acadêmica e profissionalmente por meio de manifestações e práticas corporais tematizadas nas diferentes formas e modalidades de exercícios físicos, ginástica, dança, arte/luta marciais, esporte e jogo.

Frente ao exposto, questionou-se neste estudo a inserção profissional dos egressos do curso de EF da Unifesp-BS, entendendo-se que a atuação interprofissional na perspectiva do SUS ainda não tenha uma oferta tão disponível no mercado de trabalho dos profissionais de EF. Em Hunger et al. (2006), no período compreendido entre 1991 e 2004, foi identificada a necessidade de ampliação das intervenções em EF que fossem articuladas com outras profissões da área da saúde e que essas intervenções também ganhassem espaços dentro do SUS.

Diante do exposto, os objetivos do estudo foram: compreender a inserção profissional dos egressos de um curso de EF com ênfase na formação em saúde na perspectiva do Sistema Único de Saúde; e analisar a relação desta inserção com a formação interdisciplinar e interprofissional proposta pela instituição.

\section{Método}

Foi desenvolvida uma pesquisa exploratória de abordagem qualitativa. ${ }^{6}$ Para Thomas, Nelson e Silverman (2012, p. 293), a pesquisa exploratória é “(...) um estudo do status". No caso deste estudo, o status da inserção profissional dos egressos do curso de EF da Unifesp-BS. A abordagem da pesquisa está ancorada nos pressupostos de Minayo (2012), para quem a qualitativa responde a questões muito particulares, preocupando-se com um nível de realidade que não pode ser quantificado.

O estudo analisou parte do banco de dados de uma pesquisa desenvolvida na instituição, a qual objetivou analisar o projeto de educação interprofissional na formação de saúde na ótica dos egressos com prática profissional superior a dois anos. Essa pesquisa utilizou o instrumento Readiness Interprofessional Learning Scale (RIPLS) adaptado para o Brasil por Peduzzi e Norman (2012), que contou com 26 assertivas na Escala Likert e analisou atitudes e prontidão para três fatores: Trabalho em equipe e colaboração; Identidade profissional; e Atenção centrada no paciente. A amostra total do banco de dados foi de 107 voluntários. 
Marconi e Lakatos (2010) definem questionário como um instrumento de coleta de dados formado por uma série ordenada de perguntas, que devem ser respondidas sem a presença do pesquisador. Desta forma, o recrutamento dos voluntários foi feito por e-mail enviado em forma de convite, juntamente com um termo de consentimento livre e esclarecido. Após o consentimento dos voluntários, o questionário foi disponibilizado numa plataforma online (GoogleDocs).

Em um segundo momento foram realizadas entrevistas de aprofundamento, com amostra aleatória a partir dos respondentes do RIPLS. Para Marconi e Lakatos (2010), a entrevista é o encontro entre duas pessoas, em que uma delas obtém informações de natureza profissional, para a investigação social, para coleta de dados ou para auxiliar no diagnóstico ou no tratamento de um problema social.

A coleta de dados (questionário e entrevista) foi desenvolvida ao longo do segundo semestre de 2012.

No primeiro semestre de 2013, o pesquisador responsável pelo estudo acima permitiu o acesso ao banco de dados por meio de um termo de consentimento de uso de banco de dados, bem como participou do estudo ora aqui apresentado, o qual foi aprovado pelo Comitê de Ética em Pesquisa da Unifesp.

Da amostragem inicial (107 voluntários), foram incluídos nesse estudo 15 egressos a partir dos seguintes critérios: possuir formação no curso de EF na Unifesp-BS e estar formado há dois anos.

Aplicados os critérios, tivemos a seguinte amostragem: egressos de ambos os sexos e com faixa-etária entre 23 e 29 anos, estando distribuídos pelos seguintes anos de formação: seis formados no ano de 2009 ( $1^{\text {a }}$ turma), oito formados no ano de 2010 ( $2^{\text {a }}$ turma) e um voluntário que não informou o ano de formação (mas, obrigatoriamente, é de uma dessas turmas).

Para fins de análise, o acesso ao banco de dados considerou as respostas para a seguinte questão: 'Qual seu trabalho atual?' - feita na entrevista de aprofundamento. Importante destacar que para a análise foi considerada a inserção no momento em que se respondeu ao questionário e não o que se realizou anteriormente.

Os dados foram analisados por categorias não apriorísticas, que, de acordo com Campos (2004), surgem a partir das respostas obtidas, exigindo do pesquisador o constante acesso ao material coletado, o que inicialmente exige “(...) um intenso ir e vir ao material analisado e teorias embasadoras, além de não perder de vista o atendimento aos objetivos da pesquisa" (Campos, 2004, p. 614). Nesse sentido, foi realizada uma leitura minuciosa das respostas dos voluntários incluídos nesse estudo, guiada pelo que Campos (2004) denominou de agrupamento das unidades de análise, feitas por

freqüenciamento [sic] ou 'quasi-quantitativa' (repetição de conteúdos comuns à maioria dos respondentes) ou por 'relevância implícita' (tema importante que não 
se repete no relato de outros respondentes, mas que guarda em si, riqueza e relevância para o estudo) [sic] (Campos (2004, p. 614, grifos do autor).

O estudo foi aprovado pelo Comitê de Ética e Pesquisa da Universidade Federal de São Paulo (CEP/Unifesp) e analisou parte do banco de dados do estudo de pós-doutoramento intitulado "Análise de um projeto de Educação Interprofissional na formação de saúde: ótica dos egressos", tendo a professora Rosana Aparecida Salvador Rossit como pesquisadora responsável.

\section{Resultados}

A partir das respostas dos voluntários à questão 'Qual seu trabalho atual?', foi possível obter as seguintes categorias de análise: Fitness (8 voluntários); Pós-graduação (7 voluntários); Saúde (2 voluntários).

O Quadro 1 representa a inserção dos egressos nas devidas categorias e seus respectivos anos de formação.

\begin{tabular}{|ccc|}
\hline Quadro 1 & & \\
\hline Ano de formação e Categorias & Ano de formação & Categorias \\
\hline Participante & 2009 & Pós-graduação \\
\hline 1 & Não informado & Pós-graduação e Fitness \\
2 & 2009 & Pós-graduação \\
3 & 2009 & Fitness \\
4 & 2009 & Fitness e saúde \\
5 & 2009 & Fitness \\
6 & 2009 & Fitness \\
7 & 2010 & Pós-graduação \\
8 & 2010 & Pós-graduação \\
9 & 2010 & Fitness e Pós-graduação \\
10 & 2010 & Fitness \\
11 & 2010 & Saúde \\
12 & 2010 & Fitness \\
13 & 2010 & Desemprego \\
14 & 2010 & Pós-graduação \\
15 & & \\
\hline
\end{tabular}

Fonte: Os autores.

Devido à existência de voluntários que se inseriram em mais de uma área de atuação profissional (voluntários 2, 5 e 10) foi possível chegar a 17 frequências para 15 voluntários. 
A categoria Fitness foi composta por 8 voluntários, os quais estavam inseridos nos seguintes segmentos: Personal trainer - 5 voluntários; Academias de ginástica (musculação, aulas de ginástica e aulas de natação) - 2 voluntários; Práticas corporais (artes marciais, artes circenses, educação esportiva e Serviço Social do Comércio) - 3 voluntários; Ginástica laboral - 1 voluntário; Consultoria técnica (área de fitness) - 1 voluntário; Preparação física - 1 voluntário; e Avaliação física - 1 voluntário.

O fitness, além de ser mais representativo, possuiu voluntários que atuaram em mais de uma atividade dentro das subdivisões apresentadas acima. Por isso, se somarmos o número de atividades e voluntários que as compuseram o resultado é superior a oito.

A categoria 'Pós-graduação' foi composta por 7 voluntários, a saber: Doutorado - 1 voluntário; Mestrado - 4 voluntários; Especialização - 1 voluntário; e Residência Multiprofissional - 1 voluntário.

Em relação à 'Saúde', tivemos dois voluntários, os quais estavam em atuação em: Núcleo de Apoio à Saúde da Família (Nasf) - 1 voluntário; e Clínica de medicina esportiva - 1 voluntário.

Em relação ao voluntário 14, que estava há dois meses desempregado por motivo de mudança de cidade, não consideramos que ele pudesse compor uma categoria de análise, devido aos limites do estudo. Entretanto, ressalta-se que se o estudo tivesse proposto investigar o percurso profissional após a formatura, esse voluntário estaria alocado na categoria de Fitness, pois já tinha atuado em academias e clubes.

\section{Discussão}

Até a década de 1990, a EF era referenciada particularmente como uma profissão de ambientes escolares, desconsiderando outras possibilidades (Barros, 1996). Entretanto, para o mesmo autor, foi nesta mesma época que a EF se modificou rapidamente, tanto em termos de atuação na sociedade quanto em termos de formação profissional. Nessa esteira, há a compreensão de que as possibilidades de inserção profissional em EF estão presentes em diversos contextos, principalmente para o bacharel, que pode atuar em todos os ambientes não escolares.

Entretanto, em que pese o grande horizonte de inserção profissional não escolar para o bacharel, os dados do nosso estudo apontam a área do fitness como o campo que mais absorve os egressos da Unifesp-BS, o que poderia parecer uma contradição, já que os ideários desse curso apontam para o SUS. No entanto, cabe-nos fazer três ressalvas.

Primeiramente, Proni (2010) nos alerta que o fitness é mais comum à EF, justamente pela alta oferta de emprego e por estar intrinsecamente ligado à sua atuação profissional. Nos estudos de Oliveira et al. (2013), Ramos et al. 
(2008), Furtado e Santiago (2015) e Sales, Farias e Nascimento (2015), que investigaram, respectivamente, a inserção e egressos do curso de EF da Universidade de São Paulo, Universidade Federal de São Carlos, Universidade Federal de Goiás e Universidade Federal de Santa Catarina (UFSC), a área do fitness também foi a mais representativa. Em Oliveira et al. (2013), 42\% dos egressos investigados atuavam na área do fitness (mesmos campos de atividades descritos nesse estudo), com destaque à atuação como personal trainer. Em Ramos et al. (2008), 77\% dos egressos que atuavam na área da EF também estavam na do fitness, neste caso, com destaque para as academias. Já em Furtado e Santiago (2015), a inserção na área do fitness correspondeu a 58\% dos investigados. Ainda em Furtado e Santiago (2015), a inserção do profissional de Educação Física em academias de ginástica aumentou consideravelmente nas últimas décadas. Para os autores, essa ampliação se deve a própria expansão da indústria do fitness. Em Sales, Farias e Nascimento (2015), 81\% dos egressos do curso de Bacharelado da UFSC atuavam nas áreas de atividade física, prescrição de exercícios, gestão e treinamento esportivo.

Em segundo lugar, também é fato que o PPCEF da Unifesp-BS não exclui a formação generalista; mesmo que a ênfase seja em saúde na perspectiva do SUS existe a preocupação com as “(...) diferentes formas e modalidades de exercícios físicos, da ginástica, do jogo, do esporte, da luta/arte marcial, da dança" (Unifesp-BS, 2016, p. 28).

Quanto à terceira ressalva, mesmo antes de a EF ser reconhecida como profissão da saúde, em 1997, as intervenções com vistas à atenção em saúde sempre foram desenvolvidas em outros cenários, tais como clubes, secretarias de esporte, no terceiro setor (Sesi, Sesc etc.). Nesse sentido, podemos afirmar que os achados desse estudo, principalmente aqueles listados na categoria Fitness, estão no espectro do campo da saúde. Em Rodrigues et al. (2015), por exemplo, que descrevem o perfil e aspectos da atuação de EF nos Nasf na região metropolitana de João Pessoa, na Paraíba, as atividades estiveram circunscritas à avaliação física, alongamento, caminhada e outras atividades de baixo impacto. Ou seja, não muito diferente das intervenções dos egressos do curso de EF da Unifesp-BS listados na categoria Fitness. Além disso, Furtado e Santiago (2015) afirmam que a saúde, em aliança com a estética, tem se traduzido como a principal finalidade da produção desenvolvida pelo profissional de Educação Física em academias de ginástica. Assim, consideramos a área do fitness como um campo de atuação em saúde numa perspectiva ampla.

Diante do exposto, compreendemos que os resultados apontados pela categoria Fitness não se diferem de outras perspectivas de formação em Educação Física, bem como não contradizem os pressupostos do PPCEF da Unifesp-BS.

No que se refere ao âmbito da pós-graduação, para o PPCEF da Unifesp-BS a atividade de pesquisa “(...) toma papel de destaque no processo de formação profissional" (Unifesp-BS, p. 39). Assim, é possível inferir que a pesquisa está 
inserida no curso com papel importante na formação, consequentemente, nas unidades curriculares, o que possivelmente influenciou a inserção dos egressos em cursos de pós-graduação, mesmo que, concomitantemente atuando em outras áreas. O PPCEF prevê a formação de um indivíduo que procure aliar em seu trabalho os conhecimentos científicos e a postura ética da pesquisa

Assim, pode-se dizer que há coerência entre a formação e a inserção profissional no que se refere à pós-graduação, já que dois dos objetivos específicos são claros quanto a essa questão, a saber:

- Desenvolver o espírito crítico do aluno na visão de que a graduação é apenas a formação inicial do futuro profissional; (...).

- Promover a formação continuada (Unifesp-BS, 2016, p. 29, grifo nosso).

Tal relação com a pesquisa também pode ser um indicativo de incentivo à carreira docente. De acordo com Batista e Batista (2004, p. 17), “(...) a docência no ensino superior se define, prioritariamente, pela atividade de pesquisa". Em que pese a ressalva quanto à utilização do termo 'prioritariamente' pelos autores, já que a carreira docente é desenvolvida sob o tripé ensino-pesquisa-extensão, é notório ressaltar a forte vinculação da pós-graduação com a carreira docente. Como exemplo, temos o Estágio de Docência como parte integrante e compulsória da formação de pós-graduandos bolsistas da Coordenação de Aperfeiçoamento de Pessoal de Nível Superior (Capes), o que reforça a vinculação da pesquisa com a carreira docente.

Em relação à inserção dos egressos no campo da saúde na perspectiva do SUS - saúde numa perspectiva restrita -, compreendemos que essa é a inserção profissional mais enfatizada no currículo do curso e possui relação intrínseca com o PPCEF, pois a formação para a atuação em saúde desenvolve-se ao longo do currículo em conteúdos e atividades sistematizadas fixas e/ou eletivas.

Em diferentes momentos no PPCEF é enfatizada a intervenção em saúde. “O curso de Educação Física da Unifesp articula o ensino, a pesquisa e a extensão, visando a formação profissional para atuação em Saúde" (Unifesp-BS, 2016, p. 24). No que se refere ao objetivo específico, é desejado "Propiciar base ao aluno para atuação nas diferentes áreas da Educação Física com ênfase na promoção e prevenção da saúde das pessoas" (Unifesp-BS, 2016, p. 29). E em relação aos conteúdos curriculares e organização do curso "A formação específica voltada à atuação em saúde (...)" (Unifesp-BS, 2016, p. 59).

A partir do exposto, pode-se afirmar que em relação ao conteúdo, objetivo e intervenção, o curso se organiza de modo que o olhar para a intervenção em saúde seja sempre ressaltado, deixando clara a ênfase neste modelo de formação, mesmo que, como já dito, não exclua os outros campos de atuação.

Nesse sentido, compreendemos que os dois voluntários inseridos em contextos de equipes interprofissionais de saúde, no caso deste estudo o Nasf 
e uma clínica de medicina esportiva, estão em consonância com a formação inicial recebida na instituição.

\section{Considerações finais}

Este estudo buscou compreender a inserção profissional dos egressos de um curso de EF com ênfase na formação em saúde na perspectiva do SUS, bem como analisar a relação desta inserção com a formação interdisciplinar e interprofissional proposta pela instituição.

Nesse ínterim, foi possível compreender que os egressos estão inseridos, majoritariamente, em áreas comuns à EF (academias de ginástica, personal trainer, dentre outras), bem como na pós-graduação. Esta última merecedora de destaque, sinalizando que o Bacharelado em EF na Unifesp-BS tem cumprido parte de seu papel no que diz respeito à pesquisa e à formação continuada.

Entretanto, no que se refere à inserção profissional no contexto do trabalho em saúde na perspectiva do SUS, o cenário ainda é escasso e de baixa representatividade (apenas dois de 15 voluntários). Assim, concluímos que, embora o curso de EF da Unifesp-BS proponha um modelo de formação diferenciado, ainda existem poucos campos de atuação para a referida área.

Nesse sentido, entende-se que somente parte dos preceitos do PPCEF esteja em cumprimento, restando ainda sua consolidação na inserção profissional no contexto da saúde. Tal fato, em nossa análise, não pode se relacionar somente à instituição, mas depende também de toda uma história que a própria EF precisará trilhar em relação ao SUS, o que, além de urgente, é necessário.

\section{Colaboradores}

Luana de Oliveira Candido participou da concepção do projeto de pesquisa, análise e interpretação dos dados e redação. Rosana Aparecida Salvador Rossit colaborou na concepção do projeto de pesquisa, redação e revisão crítica do estudo e Rogério Cruz de Oliveira participou da concepção do projeto de pesquisa, análise e interpretação dos dados, redação e revisão crítica do estudo e aprovação da versão final submetida. 
Resumen Los objetivos del estudio fueron comprender la empleabilidad de los graduados de un curso de educación física con énfasis en la formación en materia de salud en el contexto del Sistema Único de Salud y analizar la relación de este inserto con interdisciplinario y la formación ofrecida por la institución - en este caso la Universidad Federal de São Paulo - Campus Santos, São Paulo, Brasil. Para este fin, en 2012, se desarrolló una investigación exploratoria con enfoque cualitativo que analizó parte de la base de datos de un estudio que tuvo como objetivo evaluar el proyecto de educación interprofesional sobre formación con énfasis en la salud de la institución. De la muestra total de la encuesta (107 voluntarios) se incluyeron en este estudio 15 graduados del curso de Educación Física formados en la $1^{\text {a }}$ y $2^{\text {a }}$ clase. El análisis de datos se realizó de modo no apriorístico. Los resultados mostraron que los graduados se introdujeron en las zonas comunes de educación (gimnasios, entrenador personal, evaluación fisica, entre otros), en la posgraduación y, con menor frecuencia, en la perspectiva del Sistema Único de Salud. Se llegó a la conclusión de que todavía es pequeña la empleabilidad de profesionales de la educación física en el Sistema Único de Salud, incluso para un curso con este énfasis.

Palabras-clave educación física; personal de salud; desarrollo de personal; empleabilidad.

\section{Notas}

${ }^{1}$ Universidade Federal de São Paulo, Santos, São Paulo, Brasil.

$<$ lu.candido@ymail.com>

Correspondência: Universidade Federal de São Paulo, Campus Baixada Santista, Avenida Silva Jardim 136, CEP 11015-020, Vila Mathias, Santos, São Paulo, Brasil.

${ }^{2}$ Universidade Federal de São Paulo, Departamento de Saúde, Educação e Sociedade, Santos, São Paulo, Brasil.

$<$ rorossit@hotmail.com>

${ }^{3}$ Universidade Federal de São Paulo, Departamento de Ciências do Movimento Humano, Santos, São Paulo, Brasil.

$<$ rogerio.unifesp@gmail.com>

${ }^{4} \mathrm{~A}$ interdisciplinaridade é caracterizada pelo reconhecimento de que existe a interdependência entre as áreas científicas (Unifesp-BS, 2016). Portanto, na Unifesp-BS existe a intenção de compor uma formação ampla, na qual se discuta o indivíduo desde o ponto de vista da cultura até o biológico, viabilizando a discussão de saúde a partir de diferentes olhares.

${ }^{5}$ Considera-se educação interprofissional quando há a proposta de duas ou mais profissões aprenderem juntas sobre o trabalho em conjunto e sobre as especificidades de cada uma, visando à melhoria no cuidado com o indivíduo (Unifesp-BS, 2016).

${ }^{6}$ Essa pesquisa não obteve financiamento e é resultado de trabalho de conclusão de Curso de Educação Física desenvolvido na Universidade Federal de São Paulo-BS. 


\section{Referências}

BARROS, José M. C. Educação física: perspectivas e tendências na profissão. Motriz, Rio Claro, v. 2, n.1, p.49-52, 1996.

BATISTA, Nildo A.; BATISTA, Sylvia H. S. S. Docência em saúde: temas e experiências. São Paulo: Editora Senac, 2004.

BENITES, Larissa C.; SOUZA NETO, Samuel; HUNGER, Dagmar. O processo de constituição histórica das diretrizes curriculares na formação de professores de educação física. Educação e Pesquisa, São Paulo, v. 34, n. 2, p. 343-360, 2008.

BETTI, Irene C.R.; BETTI, Mauro. Novas perspectivas na formação profissional de educação física. Motriz, Rio Claro, v. 2, n. 1, p. 10-15, 1996.

BRASIL. Resolução n. 7, de 31 de março de 2004. Institui as Diretrizes Curriculares Nacionais para os cursos de graduação em Educação Física, em nível superior de graduação plena. Diário Oficial da República Federativa do Brasil, Poder Executivo, Brasília, DF, 5 abr. 2004.

BRASIL. Lei n. 9696, de $1^{\circ}$ de setembro de 1998. Dispõe sobre a regulamentação da Profissão de Educação Física e cria os respectivos Conselho Federal e Conselhos Regionais de Educação Física. Diário Oficial da República Federativa do Brasil, Poder Executivo, Brasília, DF, 2 set. 1998.

BRASIL. Resolução n. 218, de 6 de março de 1997. Reconhecimento de profissionais de saúde de nível superior. Diário Oficial da República Federativa do Brasil, Poder Executivo, Brasília, DF, 5 maio 1997.

BRASIL. Lei n. 9.394, de 20 de dezembro de 1996. Estabelece as Diretrizes e Bases da Educação Nacional. Diário Oficial da República Federativa do Brasil, Poder Executivo, Brasília, DF, 23 dez. 1996.

BRASIL. Resolução n. 03, 16 de junho de 1987. Fixa os mínimos de conteúdo e duração a serem observados nos cursos de graduação em Educação Física (Bacharelado e/ou Licenciatura Plena). Diário Oficial da República
Federativa do Brasil, Poder Executivo, Brasília, DF, 10 set. 1987.

BRUGNEROTTO, Fábio; SIMÕES, Regina. Caracterização dos currículos de formação profissional em educação física: um enfoque sobre saúde. Physis: Revista de Saúde Coletiva, Rio de Janeiro, v. 19, n. 1, p. 149-172, 2009.

CAMPOS, Claudinei J. G. Método de análise de conteúdo: ferramenta para análise de dados qualitativos no campo da saúde. Revista Brasileira de Enfermagem, Brasília, v. 57, n. 5, p. 611-614, 2004.

CARVALHO, Yara M.; CECCIM, Ricardo B. Formação e educação em saúde: aprendizados com a saúde coletiva. In: CAMPOS, Gastão W. S. et al. (orgs.). Tratado de saúde coletiva. 2. ed. São Paulo: Hucitec, 2012. p. 137-170.

COLLET, Carine et al. Formação inicial em educação física no Brasil: trajetória dos cursos presenciais de 2000 a 2006. Motriz, Rio Claro, v.15, n. 3, p. 493-502, 2009.

FINOQUETO, Leila C.P. As diretrizes curriculares nacionais para os cursos de graduação em educação física e impactos na produção de conhecimentos: um olhar sobre o Conbrace (2001-2007). In: CONGRESSO BRASILEIRO DE CIÊNCIAS DO ESPORTE, 17., 2011, Porto Alegre. Anais... Porto Alegre: UFRGS, 2011. p. 1-12.

FRAGA, Alex B.; CARVALHO, Yara M.; GOMES, Ivan M. Políticas de formação em educação física e saúde coletiva. Trabalho, Educação e Saúde, Rio de Janeiro, v. 10, n. 3, p. 367-386, 2012.

FURTADO, Roberto P.; SANTIAGO, Lorena P. Educação Física e trabalho: considerações a respeito dos egressos do curso de Educação Física da FEF-UFG. Revista Brasileira de Educação Física e Esporte, São Paulo, v. 29, n. 2, p. 325-336, 2015.

HUNGER, Dagmar et al. Educação Física. In: HADDAD, Ana E. et al. (orgs.) A trajetória dos cursos de graduação na saúde 1991-2004. Brasília: Inep/MEC, 2006. p. 87-139. 
MARCONI, Marina de A.; LAKATOS, Eva M. Fundamentos de metodologia científica. 7.ed. São Paulo: Atlas, 2010.

MINAYO, Maria Cecília S. Pesquisa social: teoria, método e criatividade. 31. ed. Petropólis: Vozes, 2012.

OLIVEIRA, Jorge A. et al. Área de atuação do egresso da Escola de Educação Física e Esporte da Universidade São Paulo: um retrato de formação profissional e acadêmica. Revista Mackenzie de Educação Física e Esporte, São Paulo, v. 12, n. 1, p. 65-78, 2013.

OLIVEIRA, Rogério C. de; ANDRADE, Douglas R. Formação profissional em Educação Física para o Setor da Saúde e as Diretrizes Curriculares Nacionais. Pensar a Prática, Goiânia, v. 19, n. 4, p. 721-733, 2016.

PASQUIM, Heitor M. A Saúde Coletiva nos Cursos de Graduação em Educação Física. Saúde e Sociedade, São Paulo, v. 19, n. 1, p. 193-200, 2010.

PEDUZZI, Marina; NORMAN, Ian J. Validação de instrumento de medida do aprendizado interprofissional para trabalho em equipe. In: ENCONTRO INTERNACIONAL DE PESQUISA EM ENFERMAGEM: Avanços no cuidado, gestão e política, 3., 2012, São Paulo. Anais... São Paulo: Escola de Enfermagem da USP, 2012. p. R0168-1-R0168-1.

PRONI, Marcelo W. Universidade, profissão educação física e o mercado de trabalho. Motriz, Rio Claro, v. 16, n. 3, p.788-798, 2010.

RAMOS, Glauco N. S. et al. Egressos do curso de educação física da Universidade Federal de São Carlos (1997 - 2003): formação e atuação. Movimento e Percepção, Espírito Santo do Pinhal, v. 9, n. 13, p. 249-265, 2008.

REZER, Ricardo; NASCIMENTO, Juarez V. As novas diretrizes curriculares, a regulamentação e o processo de formação: apontamentos para o campo da educação física brasileira. In: CONGRESSO BRASILEIRO DE CIÊNCIAS DO ESPORTE, 15., 2007, Recife. Anais... Recife: UFPE, 2007. p. 1-10.
RIBEIRO, Iramara L; MEDEIROS JÚNIOR, Antônio. Graduação em saúde, uma reflexão sobre ensino-aprendizado. Trabalho, Educação e Saúde, Rio de Janeiro, v. 14, n. 1, p. $33-53,2016$

RODRIGUES, José D. et al. Perfil e atuação do profissional de Educação Física nos Núcleos de Apoio à Saúde da Família na região metropolitana de João Pessoa, PB. Revista Brasileira de Atividade Física e Saúde, Pelotas, v. 20, n. 4, p. 352-365, 2015.

SALES, William N.; FARIAS, Gelcemar O.; NASCIMENTO, Juarez V. Inserção profissional e formação continuada de egressos de cursos de graduação em Educação Física. Revista Brasileira de Educação Física e Esporte, São Paulo, v. 29, n. 3, p. 475-486, 2015.

SOUZA NETO, Samuel et al. A formação profissional de Educação Física no Brasil: uma história sob a perspectiva da legislação federal do século XX. Revista Brasileira de Ciências do Esporte, Campinas, v. 25, n. 2, p. 113-128, 2004.

THOMAS, Jerry R.; NELSON, Jack K.; SILVERMAN, Stephen J. Método de pesquisa em atividade física. 6. ed. Porto Alegre: Artmed, 2012.

TOJAL, João B. Diretrizes curriculares para o bacharelado em educação física: novos rumos. Revista da Educação Física/UEM, Maringá, v. 14, n. 2, p. 105-112, 2003.

UNIFESP-BS. Universidade Federal de São Paulo. Campus Baixada Santista. Curso de Educação Física. Projeto Pedagógico do Curso de Educação Física. Santos: Unifesp, 2016.

Recebido em 04/03/2016. Aprovado em 06/02/2017. 